\title{
CORRECTION
}

\section{Correction to: Properties and Biodegradation of Thermoplastic Starch Obtained from Grafted Starches with Poly(lactic acid)}

\author{
Z. B. Cuevas-Carballo ${ }^{1} \cdot$ S. Duarte-Aranda ${ }^{1} \cdot$ G. Canché-Escamilla ${ }^{1} \mathbb{C}$
}

Published online: 13 February 2020

(c) Springer Science+Business Media, LLC, part of Springer Nature 2020

\section{Correction to: \\ Journal of Polymers and the Environment (2019) \\ 27(11):2607-2617 \\ https://doi.org/10.1007/s10924-019-01540-w}

The original version of this article unfortunately contained an error in Reference 7. The correct reference 7 should read as the following:

7. Esmaeili M, Pircheraghi G, Bagheri R, Altstädt V (2019) Polym Adv Technol 30:839

Publisher's Note Springer Nature remains neutral with regard to jurisdictional claims in published maps and institutional affiliations.

The original article can be found online at https://doi.org/10.1007/ s10924-019-01540-w.

G. Canché-Escamilla gcanche@cicy.mx

1 Centro de Investigación Científica de Yucatán, A.C., Calle 43 No. 130, Col. Chuburná de Hidalgo, C.P. 97205 Mérida, Yucatán, Mexico 